\title{
A RELAÇÃO ENTRE PESQUISADORES E ESCOLAS PÚBLICAS: UM DIÁLOGO A PARTIR DO TEMPO LIVRE ${ }^{1}$
}

\author{
Jorge Castellá Sarriera \\ Universidade Federal do Rio Grande do Sul, Porto Alegre, Brasil \\ Universidade do Rio dos Sinos, São Leopoldo, Brasil \\ Zuleika Köhler Gonzales Zandonai \\ Júlia Schneider Hermel \\ Paula Nunes Mousquer \\ Roberta Paula Schell Coelho \\ Pontifícia Universidade Católica do Rio Grande do Sul, Porto Alegre, Brasil
}

RESUMO: Este artigo é um relato de experiência no desenvolvimento da pesquisa intitulada: Tempo Livre de Adolescentes de Classe Popular: Bem-estar ou Comportamento de Risco? A partir da apresentação e discussão dos resultados com as escolas participantes deste estudo, despertou-nos o interesse de refletir sobre a relação entre Universidade Escolas Públicas. Através do encontro destes dois territórios se estabeleceu um espaço propício para problematizarmos temas como: controle das instituições dirigido aos alunos; a passividade destes nas suas escolhas pessoais; o estranhamento das escolas diante do novo, daquilo que coloca em risco sua autoridade e poder; e as expressões e atitudes destes adolescentes uma vez inseridos numa prática reflexiva.

PALAVRAS-CHAVE: Relato de experiência; tempo livre; pesquisa em escola.

\section{THE RELATIONSHIP BETWEEN RESEARCHERS AND PUBLIC SCHOOLS: A DIALOGUE ISSUING FROM FREE-TIME}

ABSTRACT: This article is a report of our experience as researchers in Community Psychology involved with a project entitled "Lower Classes Adolescent's Free Time: Well-being or Risk Behavior?" The presentation and discussion of its results incited us to investigate the connection between University and Public Schools. The meeting of these two territories established a propitious space to discuss subjects such as: the control of students by the institutions; the passivity of students concerning their own personal choices; the discomfort of the school in face of changes, that may challenge its authority and power; and the expressions and attitudes of these adolescent's once they're included in the practice of contemplation.

KEYWORDS: reports of experience; free-time; school research.

Este relato é um recorte num percurso de pesquisa acadêmico, sendo resultado do processo de apresentação e discussão dos dados de pesquisa desenvolvida intitulada: Tempo livre de adolescentes de classe popular: Bem-estar ou comportamento de risco? Situa-se, portanto, no momento em que retornamos às escolas públicas que deram origem à investigação, um ano após o primeiro encontro.

A temática da pesquisa torna-se relevante na medida em que o tempo livre é fundamental para a experimentação e elaboração das identidades necessárias para a inserção social. É um espaço temporal que privilegia o estabelecimento de relações interpessoais, a tomada de consciência por parte do adolescente de sua originalidade e criatividade. Ao mesmo tempo, prepara o adolescente para o desenvolvimento de funções sociais na possibilidade de vivenciar múltiplos papéis na ludicidade dos tempos de lazer. A sociabilidade é evidenciada nestes momentos, ao possibilitar a prática de escolhas, a capacidade de tomar iniciativas e a decisão de tornar-se um elemento com maior ou menor autonomia frente aos grupos e às redes sociais. Em nossa prática de pesquisa evidenciam-se estas funções do tempo livre corroborando com autores revisados, tais como Carrano (2003), Codina (2002) e Zamora, Toledo, Santi e Martinez (1995).

Temos como objetivo, relatar a experiência no encontro com as escolas participantes da pesquisa, buscando discutir como tal encontro se configurou, neste momento específico de apresentação e discussão dos resultados previamente analisados pelos pesquisadores. A partir deste momento de encontro entre pesquisador-pesquisado vieram os estranhamentos, a familiaridade, a curiosidade, as resistências, os silêncios e as falas. Reconhecemos a existência desta rede de forças e sentimentos. Com isto, nos veio a necessidade de discutir a maneira como se deu a relação entre pesquisadores e universo de pesquisa - a temática do tempo livre, o espaço escolar, a demanda social sobre os adolescentes escolarizados e seus professores, e a nossa visão a partir da universidade - atribuindo a estes elementos possíveis significações.

Esperamos, com este artigo na qualidade de relato de experiência, incitar alguma reflexão acerca da importância 
do diálogo entre pesquisadores e pesquisados. Para tanto, apresentamos inicialmente os aspectos metodológicos da pesquisa bem como alguns resultados alcançados, para a seguir relatarmos nossa experiência e considerações sobre a mesma.

\section{Método da Pesquisa}

Constituíram-se participantes do estudo 159 adolescentes de ambos os sexos, com idades entre os 12 anos e os 18 anos incompletos, estudantes de quinze escolas públicas de Porto Alegre-RS. As escolas foram identificadas a partir de informações obtidas junto a Secretaria de Educação do Rio Grande do Sul e Delegacia de Educação de Porto Alegre, sendo selecionadas aquelas que se caracterizam pelo atendimento a jovens de classe popular localizadas em zonas periféricas. A partir da permissão das escolas, os alunos foram convidados a participar da pesquisa, sendo encaminhado aos pais ou responsáveis legais o termo de consentimento informado.

Os instrumentos utilizados para a coleta de dados quantitativos foram um questionário socioeconômico e uma tabela na qual constavam os sete dias da semana divididos em períodos de duas horas, na qual os adolescentes deveriam escrever as atividades realizadas durante as vinte e quatro horas de cada dia da semana, assinalando com um círculo aquelas consideradas de tempo livre. Para a análise qualitativa dos dados, foram realizados 15 grupos focais: 8 grupos com adolescentes de 12 a 14 anos e 7 com adolescentes de 15 a 18 anos incompletos, nos quais foi proposta a discussão do tema Tempo Livre. Portanto, em cada uma das 15 escolas participantes da pesquisa foi realizado um grupo focal.

Os dados da tabela foram analisados através de estatística descritiva-inferencial, utilizando-se distribuição de frequiências, percentuais e teste de associação de qui-quadrado. As verbalizações dos grupos focais foram gravadas e transcritas, sendo posteriormente realizada a análise de conteúdo e a partir desta construída a "Matriz Compreensiva de Dados", referente ao significado e à valoração do tempo livre para esses adolescentes.

\section{Principais resultados alcançados}

A "Matriz Compreensiva dos Dados" contempla dois eixos. O primeiro é relativo ao Significado do Tempo Livre e compõe-se de três grandes categorias: Tempo de Liberdade, que expressa o desejo dos jovens de autodeterminarem suas atividades e não terem compromisso e controle externo no seu tempo; Tempo de Prazer, relativo aos momentos em que o adolescente sai de sua rotina e obtêm satisfação mediante a realização de atividades de forma individual ou coletiva, principalmente com o grupo de amigos; e Tempo de Ócio, que diz respeito às finalidades de cada atividade realizada no tempo livre: descanso, diversão e/ou desenvolvimento da personalidade. O segundo eixo está relacionado à Valoração do Tempo Livre e se compõe de duas categorias: Sentimento Produzido, que expressa a valoração desse tempo a partir dos sentimentos de satisfação ou insatisfação experimentados; e Julgamento Moral, que apresenta a valoração do tempo livre em termos de percepção das atividades realizadas, como corretas ou incorretas.

Com relação ao uso do tempo livre, verifica-se que, durante a semana, as atividades mais citadas pelos adolescentes foram de descanso, higiene e alimentação, assistir televisão e trabalhar. Com menor freqüência foram mencionadas as atividades escolares, domésticas e deslocamentos. No tempo livre nos finais de semana ainda prevalecem as atividades de descanso, higiene, alimentação e assistir televisão, entretanto, aumentam as atividades de lazer fora de casa, tais como atividades sócio-recreativas, esportivas e sair com amigos.

\section{Procedimentos para apresentação dos resultados}

No processo de apresentação dos dados da pesquisa foi retomado o contato com as escolas participantes a fim de apresentar e discutir os dados junto aos adolescentes, sendo solicitada à supervisora educacional de cada escola a disponibilidade de turmas e horários para a apresentação dos resultados. A marcação das turmas baseou-se principalmente na previsão da série escolar que os alunos participantes deveriam estar cursando, tomando como referência a série que estavam no momento da realização da pesquisa no ano anterior.

OGrupo de Pesquisa em Psicologia Comunitária(GPPC) elaborou ao todo sete cartazes contendo os principais resultados da pesquisa. A confecção dos cartazes priorizou a comunicação visual, utilizando cores e imagens que tornassem a visualização das informações de forma atrativa para os adolescentes. O conteúdo dos cartazes incluiu a apresentação do grupo de pesquisa, a descrição dos objetivos da devolução, os procedimentos da pesquisa, os resultados e as considerações parciais. Em média esse encontro durava cerca de 40 minutos, na maioria das vezes ocorrendo no auditório da escola ou na sala de aula onde a turma escolhida se encontrava. A devolução foi realizada por membros do GPPC - doutorandas, mestrandas e bolsistas de iniciação científica. Estiveram presentes, além dos alunos, a professora da turma daquele período e, em algumas escolas, a supervisora educacional.

\section{Discussão: o encontro com os participantes da pesquisa}

Nos estudos sobre o tempo livre dos adolescentes muitas dimensões se entrecruzam nas práticas de pesquisa e 
nos espaços educacionais percorridos. Na medida em que o tempo se constitui como um domínio a conhecer, inevitavelmente os mecanismos produtores de saberes atravessam as nossas elaborações a respeito do "tempo livre", já que falamos a partir de lugares - instituições "autorizadas" a avalizar o conhecimento. No decorrer da pesquisa, os adolescentes significam tempo livre, em sua maioria, como ausência de controle, de obrigação, de hierarquia e como um tempo de liberdade para além das instituições reguladoras da sociedade. Isso nos coloca em xeque pela demanda a que nos propomos, ou seja, falar de algo que se funda na liberdade, porém, a partir de espaços-lugares que delimitam e controlam a dimensão do saber e das escolhas e posturas frente à vida, sobretudo neste período de escolarização.

Numa postura sensível perante a pesquisa, revimos os caminhos trilhados, os direcionamentos tomados e os efeitos produzidos nesta trajetória a partir dos encontros com outros campos de saber entrecruzados. Significamos a nossa experiência reconhecendo que também fazemos parte destas realidades estudadas e que esta situação influencia nossas percepções e análises. Ao pensar numa investigação que se conscientiza na medida em que damos sentidos ao que produzimos, não partimos de uma perspectiva de realidade a priori, já que esta se dá no nosso fazer (Barros de Barros \& Lucero, 2005). Nesta mesma direção, Barros de Barros e Lucero concebem uma investigação embasada no sentido que damos ao mundo ao produzilo, pois não é a busca de uma verdade sobre uma realidade apriorística ao nosso fazer, "já que não há uma perspectiva privilegiada a partir da qual possamos ver e entender melhor a realidade" (p. 12). É assim que procuramos sair do "velho" lugar destinado às universidades, na qual nos consideramos os detentores de conhecimento, que vão à sociedade, como se em outro lugar estivesse, para depois promover alguns ensinamentos.

Nas nossas idas às escolas, nos primeiros contatos, nos chamaram atenção os modos de estruturação do espaço escolar, no que tange a situações de controle, disciplina e segurança. A maioria das escolas participante da pesquisa caracterizava-se pela precariedade, pela ausência tanto de infra-estrutura nas salas de aula quanto de espaços destinados ao lazer, tais como quadras esportivas e praças. Além da falta de recursos, nos chamou atenção o excessivo controle físico existente nestas escolas. A presença de grades, de cadeados nos portões e até mesmo de seguranças com cacetetes nos sugeriu demasiada "proteção" e busca de isolamento destas escolas. Tal isolamento possivelmente é adotado visando uma maior segurança para a escola, protegendo professores e alunos da "violência exterior". Porém, uma vez que as grades e os seguranças impedem a ocorrência do assalto, do tráfico e da criminalidade, dificultam também a aproximação de algo novo, a experimentação de uma nova situação.
A estrutura física demarcando a relação entre o interno e o externo ao meio escolar, as suas fronteiras, delimitando o que fica dentro e o que fica fora, impõe formas de apropriação e de legitimação deste espaço como próprio à cultura escolar, afastada das "casas", da rua e do meio no qual se encontra. Impõe a ruptura da cultura escolar com os instantes inesperados do cotidiano, introduz uma vinculação com o modelo pedagógico da era moderna, centrado numa temporalidade do ritmo da produção e das fábricas bem como do conhecimento racional em busca de verdades universais e não condizentes com as realidades das escolas.

Este cenário nos remete ao pensamento arendtiano sobre as condições da existência humana, das atividades humanas e dos espaços em que se dão estas atividades. Fazendo uma leitura a partir de Arendt, os autores Bárcena e Mélich (2000), apontam a educação como "uma ação ética, fundada na liberdade, pois evoca a criação de um mundo novo de possibilidades, de um novo começo, de uma natalidade. O poder sempre aberto à força do que nasce"(p. 72). Por outro lado, os autores entendem o processo educativo contemporâneo como um processo de fabricação, como uma atividade de "trabalho". Nessa lógica da fabricação, não há espaço para criação e para a novidade que propiciam algum tipo de mudança (Bárcena \& Mélich, 2000; Enguita, 1989). Surge, pois, o modelo educacional dominante (Gadotti, 2000; Morin, 2002), com pedagogias centradas na transmissão cultural, guiadas pela necessidade da previsão, do sistema de moldagem, do controle sobre todo o processo de aprendizagem e da expectativa de um resultado pré-determinado. É neste paradigma, que nos reconhecemos. Numa educação que elimina a novidade, a imprevisibilidade e a surpresa.

As escolas, no geral, eliminam a possibilidade dos alunos se depararem com uma nova forma de pensar, de agir, de problematizar a situação atual. Verificamos esta resistência das escolas públicas para com a novidade no momento em que realizamos a apresentação e discussão dos dados de nossa pesquisa. Causávamos estranheza com a nossa presença, incomodávamos em alguns casos por solicitar uma "quebra na rotina" das programações de cada turma. Aonde se "encaixaria" o conteúdo abordado por nós? A sensação em muitos momentos era de que importava falar com os adolescentes sobre os seus tempos vividos para nós - e para eles, depois que se deixavam transgredir para além da ordem instituída dos tempos e conteúdos programáticos do sistema educativo.

A educação enquanto fabricação vem sendo questionada há algum tempo por educadores como Mariano Enguita (1989) e Paulo Freire (1999). Até que ponto a escola está desempenhando seu papel de auxílio na formação pessoal e profissional do adolescente, se apenas há espaço para a reprodução de conhecimentos? Como tornar a educação uma prática de ação e não de fabricação humana? 
A inovação não pode ser decorrente do desenvolvimento de espaços de criação nestas escolas? Daí o foco de nossas questões: lidar com algo da ordem da liberdade num espaço que refuta esta possibilidade. Essas questões nos acompanharam no dia a dia da pesquisa, fazendo com que refletíssemos acerca dos sentimentos despertados nos jovens, já que esses possuem vivências diárias em espaços tão controlados.

Em algumas escolas tiveram grupos que se manifestaram através de um silêncio atrelado ao descaso com os resultados da pesquisa, levando-nos a pensar o quanto de passividade estava manifesta naquele silêncio. $O$ silenciar para os pesquisadores sugere um silenciar para a temática do tempo livre, nos faz pensar na não-adoção de uma postura crítica destes jovens acerca das atividades realizadas nos momentos em que podem ser protagonistas de suas escolhas e até de uma demanda do espaço escolar retirando essa possibilidade dos adolescentes. Um exemplo desse controle está relacionado ao silêncio exigido para manutenção da ordem escolar, presenciado numa das apresentações, quando uma professora nos interrompeu para "xingar" dois alunos, que não "prestavam atenção" no que dizíamos sobre o tempo livre. Junto a isso, questionamos o quanto o jovem é movido pela energia da novidade e como essa energia atemoriza quem domina. Nessa situação o elemento chave é a figura de autoridade. É através da força que ela "autoriza" quem entra e quem sai da escola; impondo limites entre o espaço interno e externo.

Interessante é que nos espaços com maior pluralidade, maior abertura, como numa escola em que as práticas educativas vão para além das tradicionais aulas em sala de aula - a escola oferece várias atividades aos alunos tais como capoeira, balé, banda da escola, mostra de talentos - o diálogo estabelecido entre pesquisadores e adolescentes fluía num falar significativo do que lhes acontece, colocando afeto nas situações vividas. Ali, os alunos "falaram" de nem sempre serem "ouvidos" sobre o que eles gostariam de fazer, dizendo não ter muita discussão quando as atividades são propostas, mas o importante é que isto lhes afeta, lhes impulsiona a dizer do que lhes falta.

As imagens da instituição escolar que perduram em nossos afetos, de alguma forma nos inquietam, sobretudo ao pensar nas demandas colocadas sobre a educação como uma possibilidade de transformação social, de ruptura com o que está instituído e a emergência de novos modos de ser. Sobressai a visão de um espaço com muito descuido, de abandono; qual a relação com a violência? Com o silêncio dos alunos em sala de aula? Que lugar é este no qual se instaurou o abandono do espaço, das pessoas, ao mesmo tempo que é cheio de grades, portões, violência? Qual a relação entre este cenário de abandono, de descuido, e o tempo livre não disponível? Estaria na ordem do "não se tem dinheiro", de um tempo livre relacionado a recursos financeiros? Seria ainda um espaço evidenciando um lugar de escrachada exclusão social, na fronteira do abandono e do reconhecimento pela violência? Destacamos que o maior entrave da relação entre os pesquisadores e as escolas públicas pesquisadas foi a dificuldade de aproximação dos pesquisadores com o sistema público educacional, visto a quantidade de implicações impostas para uma possível abertura de troca de saberes. Verificamos que o espaço concedido à pesquisa é limitado, uma vez que a novidade (novas propostas, novas maneiras de pensar e rever a prática educacional) é ameaçadora pela sua capacidade de provocar transformações. Tais mudanças são temidas pelas figuras de autoridade, pois seu controle poderá se desestabilizar.

\section{Considerações}

O que destacamos nessa experiência foi uma aprendizagem a partir dos sentidos, dos olhares, das falas, das expressões, e não somente através das informações concretas, dos resultados da pesquisa. Percebemos que falar sobre uma temática que diz respeito diretamente aos adolescentes pode gerar certa inquietação no início do encontro, mas no decorrer do trabalho observamos que os resultados remetem às vivências de cada adolescente presente através das reações produzidas. Então, na medida em que a temática do tempo livre fazia maior sentido, o grupo participante demonstrava interesse pelo assunto abordado, fazendo daquele encontro um exercício de uma prática reflexiva. Desta forma, ao propor uma discussão dos resultados alcançados, abrimos espaço para uma maior visibilidade, por parte dos alunos, sobre a importância desta temática uma vez que lhes foi possibilitada a expressão de idéias, a reflexão de suas práticas de vida e a percepção de seus processos psíquicos e sociais.

Consideramos que este retorno às escolas caracterizouse como um momento fundamental no processo de análise, interpretação e validação dos resultados previamente analisados. Além disso, esta experiência contribuiu para maior compreensão da temática do tempo livre em adolescentes de classe popular, bem como para o fortalecimento do vínculo entre pesquisadores e participantes da pesquisa.

\section{Notas}

1 A pesquisa que deu origem a esse artigo foi financiada pelo CNPq e FAPERGS, sendo desenvolvida pelos seguintes membros do Grupo de Pesquisa em Psicologia Comunitária, além dos autores: Tais Nicoletto Bonato, Marli Appel da Silva, Ángela Paradiso, Kátia Biehl, Maria Piedad Rangel Meneses, Gabriella Howes e Joana Bücker.

\section{Referências}

Bárcena, F. \& Mélich, J. (2000). La educación como acontecimiento ético-Natalidad, narración y hospitalidad. Barcelona, España: Paidós. 
Barros de Barros, M. E. \& Lucero, N. A. (2005). A pesquisa em Psicologia: Construindo outros planos de análise. Psicologia \& Sociedade, 17(2), 7-13.

Carrano, P. C. R. (2003). Juventudes e cidades educadoras. Petrópolis, RJ: Vozes.

Codina, N. (2002). El ócio en el sistema complejo del self. In M. J. Cava. Propuestas alternativas de investigación sobre ócio (pp. 57-72). Bilbao, España: Universidad de Deusto, Instituto de Estúdios de Ócio.

Enguita, M. (1989). A face oculta da escola. Porto Alegre, RS: Artes Médicas.

Freire, P. (1999). Pedagogia da autonomia. São Paulo, SP: Paz e Terra.

Gadotti, M. (2000). Perspectivas atuais da Educação. São Paulo em Perspectiva, 14(2), 03-11.

Morin, E. (2002). Os sete saberes necessários à educação do futuro (6. ed.). São Paulo, SP: Cortez; Brasília, DF: UNESCO.

Zamora, R., Toledo, M., Santi, P. \& Martinez, M. (1995). El tiempo libre y la recreación: Estudio en adolescentes uruguayos. In R. Zamora, M. Toledo, P. Santi \& M. Martinez. La salud del adolescenteydel jóven (pp. 533-544). Washington, DC: Matilde Madaleno.

Jorge Castellá Sarriera é doutor em Psicologia, mestre em Psicologia Escolar. Pesquisador do CNPq e membro do Comitê de Assessoramento (CNPq). Professor convidado pela Universidade Federal do Rio Grande do Sul - UFRGS. Professor colaborador do Programa de Pós-Graduação em Saúde Coletiva da Universidade do Rio dos Sinos - UNISINOS. Coordenador do Grupo de Pesquisa em Psicologia Comunitária desde 1993. Endereço para correspondência: Rua Álvares Machado, 120, apto. 502 - Porto Alegre - RS. CEP 90630-010. sarriera@terra.com.br
Zuleika Köhler Gonzales Zandonai é psicóloga, mestranda do Programa de Pós-Graduação da Pontifícia Universidade Católica do Rio Grande do Sul - PUCRS. Especialista em Psicologia de Grupos.

$$
\text { zuleika3012@yahoo.com.br }
$$

Júlia Schneider Hermel é bolsista de Iniciação Científica da FAPERGS, membro do Grupo de Pesquisa em Psicologia Comunitária e graduanda do $8^{\circ}$ semestre da Faculdade de Psicologia da PUCRS.

$$
\text { juliahermel@yahoo.com.br }
$$

Paula Nunes Mousquer é bolsista CNPq-PIBIC, membro do Grupo de Pesquisa em Psicologia Comunitária e graduanda do $5^{\circ}$ semestre da Faculdade de Psicologia da PUCRS. paula.mousquer@gmail.com

Roberta Paula Schell Coelho é bolsista de Iniciação Científica do CNPq, membro do Grupo de Pesquisa em Psicologia Comunitária e graduanda do $8^{\circ}$ semestre da Faculdade de Psicologia da PUCRS. betacanada@hotmail.com

\section{A relação entre pesquisadores e escolas públicas: um diálogo a partir do tempo livre}

Jorge Castellá Sarriera, Zuleika Köhler Gonzales Zandonai, Júlia Schneider Hermel, Paula Nunes Mousquer e Roberta Paula Schell Coelho

Recebido: 18/05/2006

$1^{\mathrm{a}}$ revisão: $19 / 08 / 2006$

$2^{a}$ revisão: 20/11/2006

Aceite final: 26/12/2006 